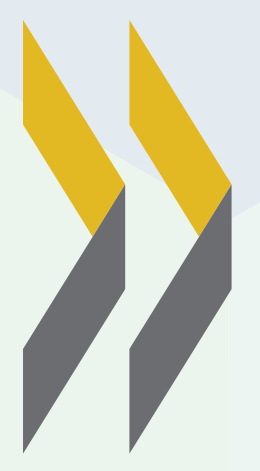

\title{
How does PISA measure students' ability to collaborate?
}

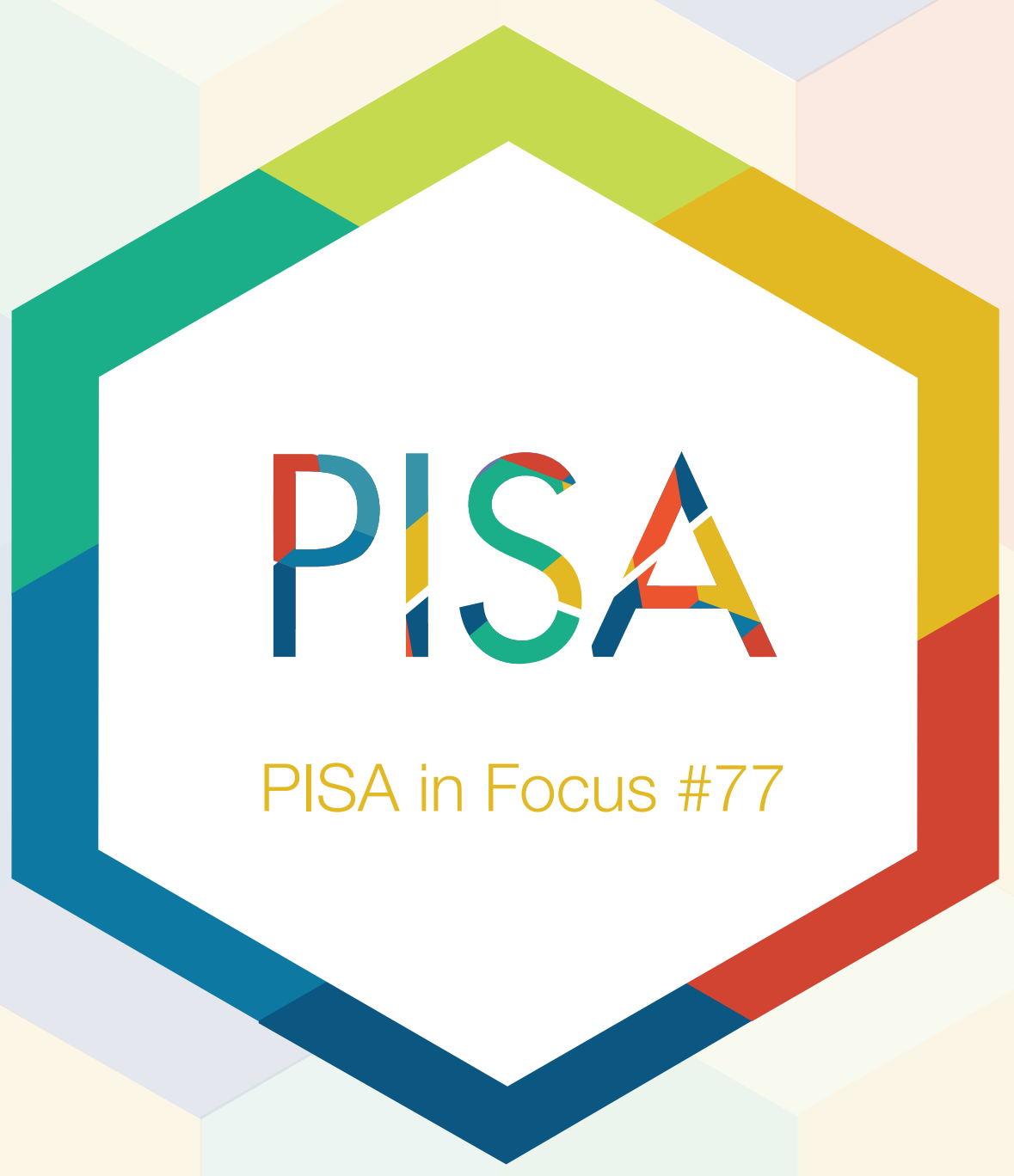




\section{How does PISA measure students' ability to collaborate?}

- Results from the PISA 2015 collaborative problem-solving assessment will be released on 21 November 2017.

- The PISA 2015 collaborative problem-solving assessment is the first international test of students' ability to work with others to solve problems.

- Around 125000 students in 52 countries and economies participated in the assessment.

Every three years, PISA measures students' competencies in science, reading and mathematics. Mastering the core school subjects and applying one's knowledge to familiar settings, however, is not sufficient to thrive in life. Even in the absence of specific knowledge or of a routine procedure on which they can rely, students must still be able to understand and solve the many new problems they will encounter. For this reason, PISA 2012 assessed students' ability to solve problems individually.

Solving unfamiliar problems on one's own is important, but in today's increasingly interconnected world, people are often required to collaborate in order to achieve their goals, both in the workplace and in their personal lives. Teamwork has numerous benefits: a diverse range of opinions and prior experiences can be drawn upon; there may be synergies among team members, resulting in better and more efficient solutions; and labour can be divided and tasks assigned to those who are best at each of them.

Collaboration can also be fraught with difficulties. Instead of dividing tasks effectively, one team member might end up reproducing another's work. Interpersonal tension and poor communication within the team might also prevent it from achieving its full potential. Working with others is a skill that might not be natural to everyone, but that can be developed with time and practice.

Hence, PISA 2015 goes beyond individual problem solving and - for the first time ever in any international assessment - measures students' ability to solve problems collaboratively. Students in 52 education systems completed this assessment.

\section{What does it mean to be competent in collaborative problem solving?}

One of the six units used in this computer-administered assessment, Xandar, has been released to the public. In Xandar, the student sitting the assessment is part of a team (a little more on that later) that must answer questions in a quiz show-like contest about the fictional country of Xandar.

In 2012, PISA identified four processes that make up individual problem solving:

- gathering information related to the problem

- representing the problem and the various relationships in the problem with tables, graphs, symbols or words

- devising a strategy to solve the problem and carrying out this strategy

- ensuring that the strategy has been followed and reacting to feedback obtained during the course of solving the problem.

These four processes are still relevant to the problem-solving aspects of the PISA 2015 collaborative problemsolving assessment. In addition, there are three competencies specific to collaborative problem solving:

- establishing and maintaining shared understanding (finding out what other team members know and ensuring that team members share the same vision of the problem)

- taking appropriate action to solve the problem (determining what collaborative actions need to be performed - for example, who does what? - and then executing these actions) 
- establishing and maintaining team organisation (following one's own role in the problem-solving strategy and checking that others also follow their assigned role).

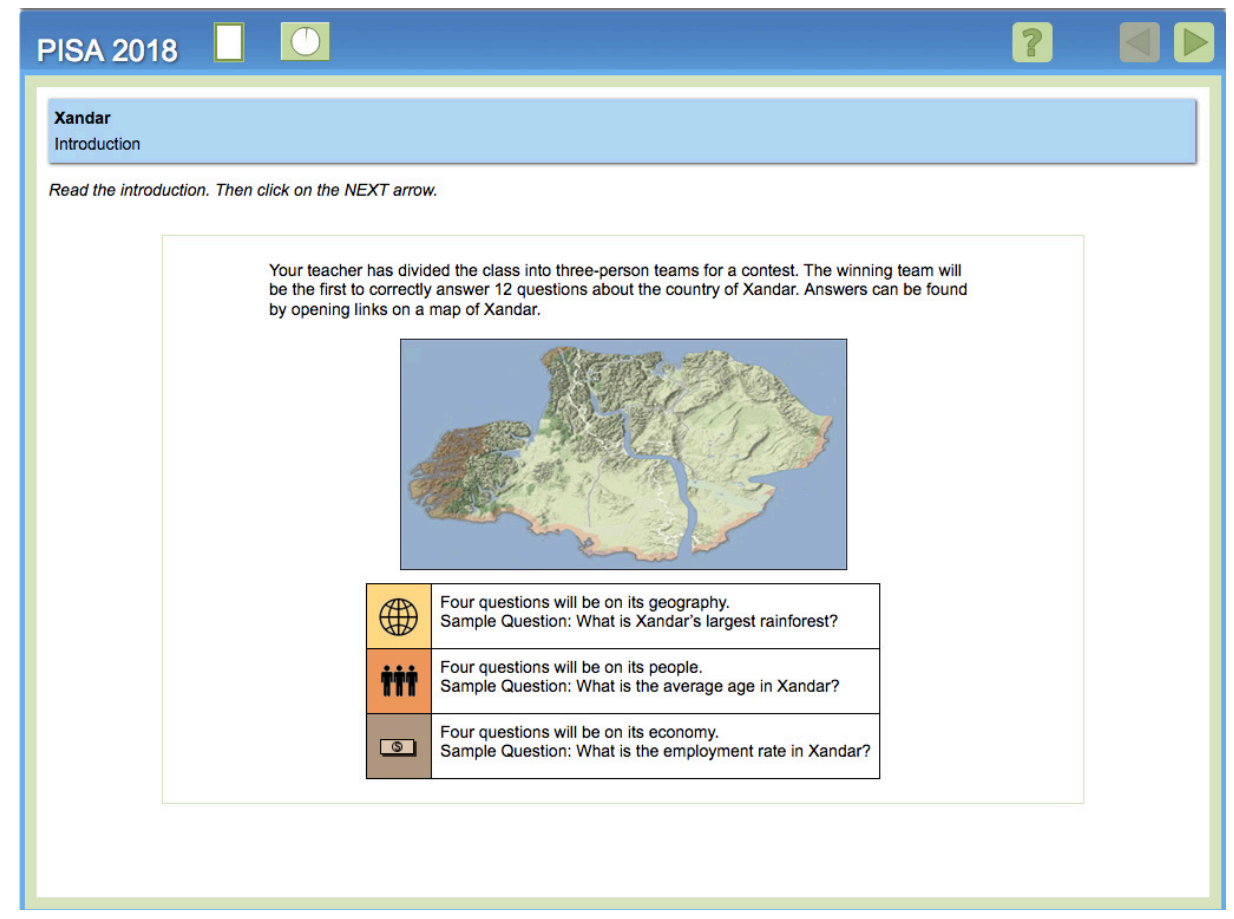

The four individual problem-solving processes and the three collaborative problem-solving competencies together identify 12 specific skills. Each of the items in the collaborative problem-solving test assesses at least one of these specific skills.

Take, for example, the items in the unit Xandar:

- In Task 1, Item 2, one of the team members wants to discuss how to approach the contest, while another team member just wants to get started. A test-taker who agrees with the first student and wants to first discuss strategy would receive credit for this response, as he or she is "devising a strategy" to solve the problem and "establishing and maintaining shared understanding".

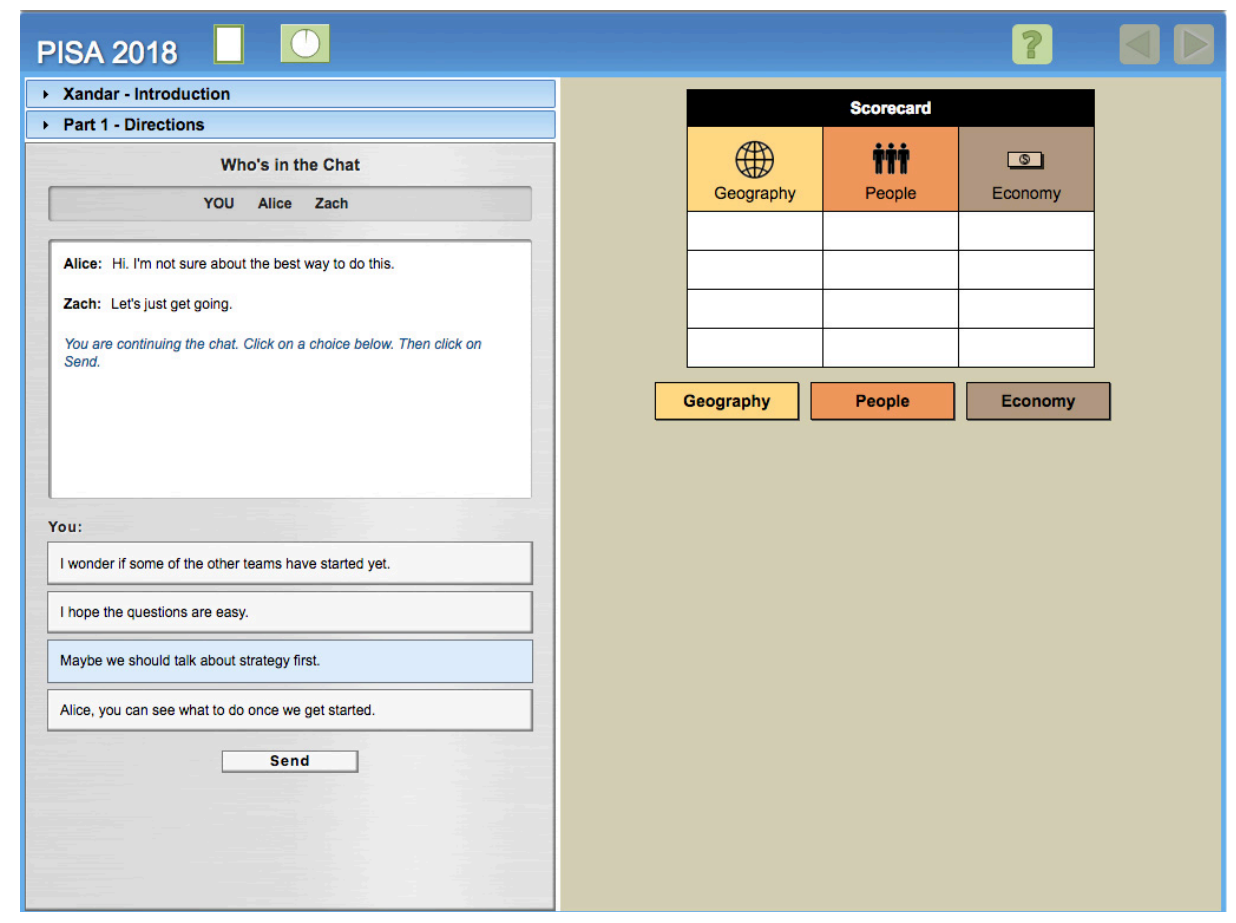


- In Task 2, Item 2, after establishing a strategy wherein each team member answers his or her own set of questions, two team members want to tackle the same set of questions. One of the students has provided a better reason than the other as to why she wants to respond to this set of questions, and the test-taker must assign this set to that student. A student who does this "represents the problem" and "establishes and maintains team organisation".

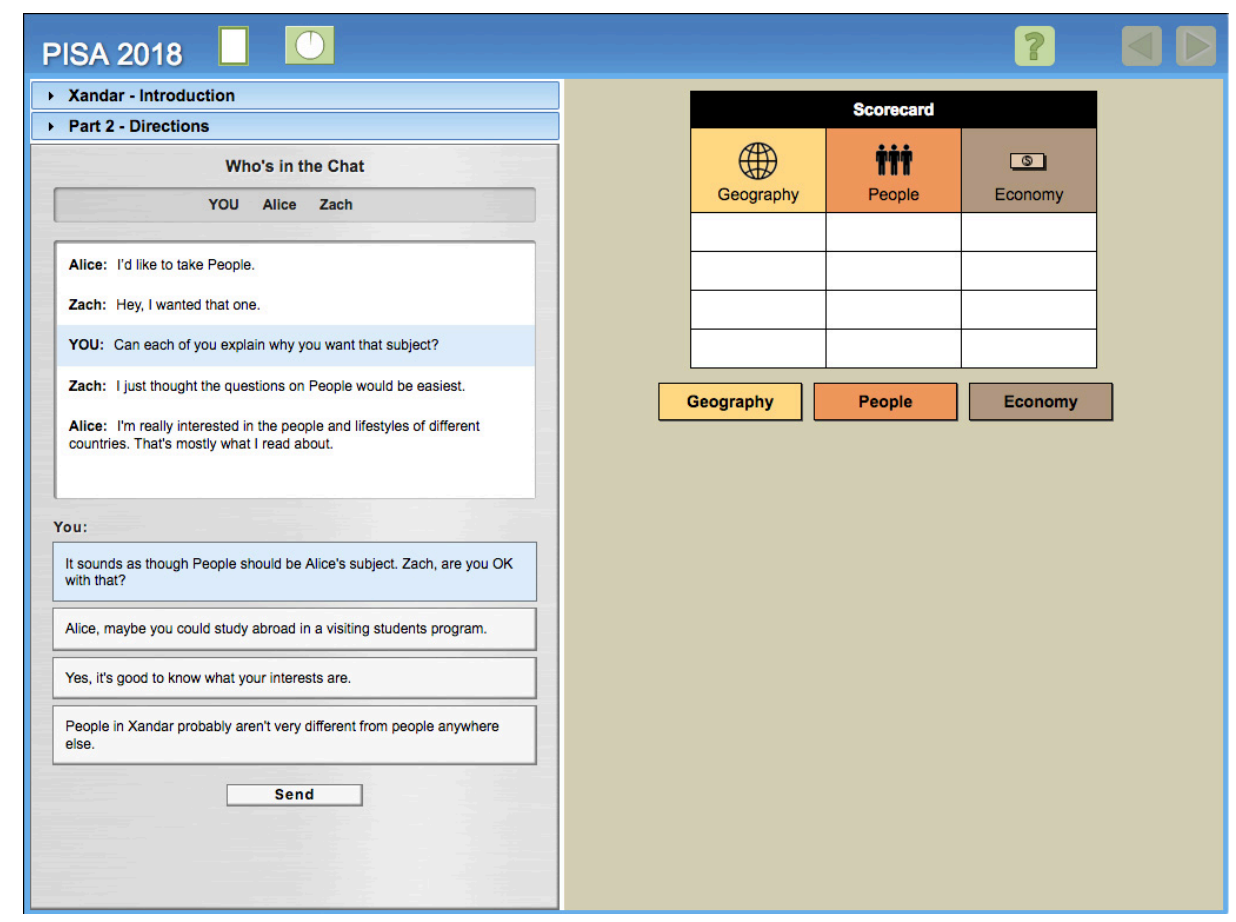

- In Task 4, Item 2, the test-taker must look at the scorecard and realise that the team is lagging behind in one of the question categories. If the test-taker does this, then he or she is competent in "ensuring the strategy has been followed" and in "taking appropriate action to solve the problem".

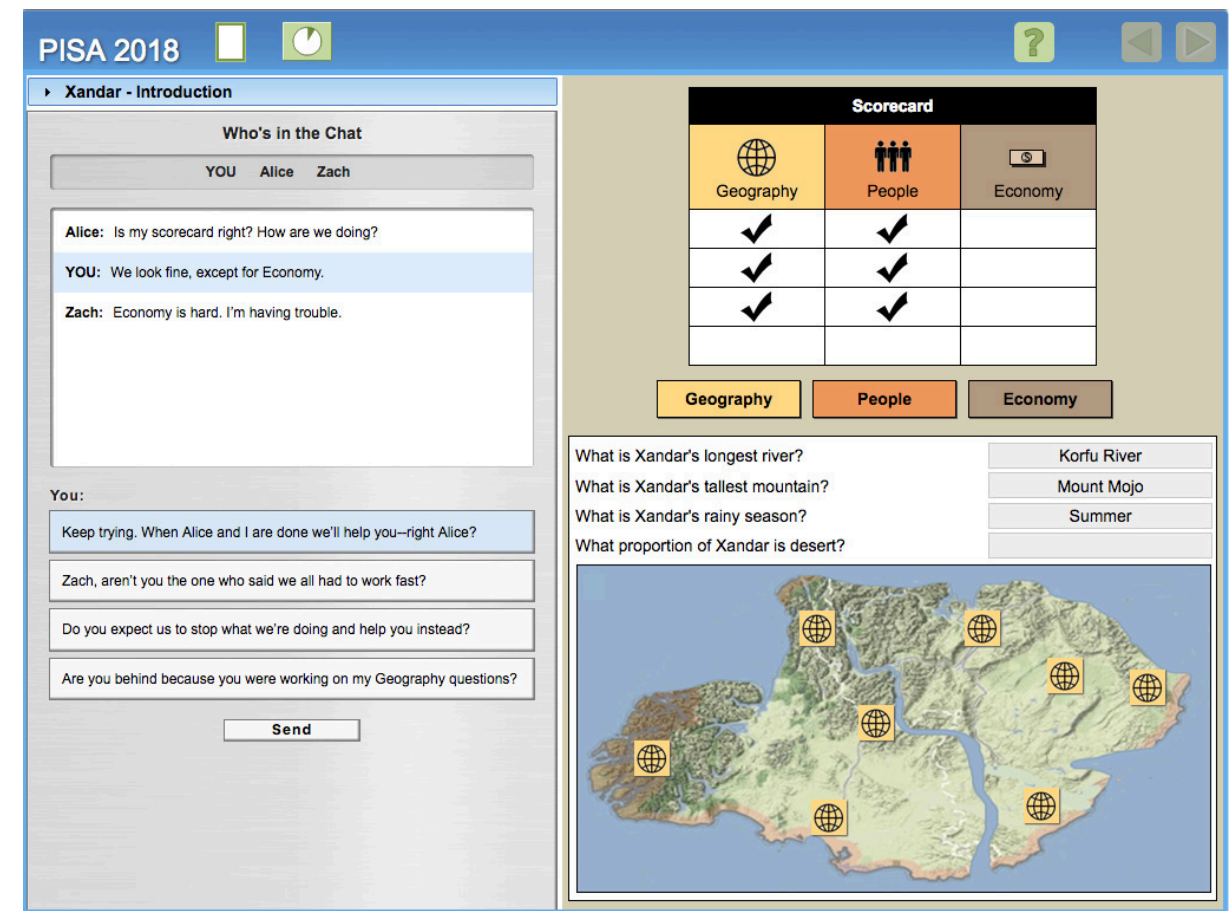




\section{With whom do students collaborate in this assessment?}

In real life, people generally communicate with other people; increasingly, they do so through computers or phones. In order to provide an accurate measure of students' collaborative problem-solving ability - one that does not depend on their partners' performance - PISA took advantage of computer-based delivery and let students interact with computer simulations of humans (known as computer agents) whose behaviour can be controlled. No matter how the test-taker responds, these computer agents bring the problem back to the same state. Students face the same set of decision points regardless of their previous decisions. The computer agents can also be programmed so that some are more co-operative than others, and some may be more focused on solving the problem than others - just as humans would be.

But are human-computer interactions an accurate approximation of human-human interactions? A study commissioned by the OECD found that:

- There were no practically relevant differences between how students responded to two versions of the collaborative problem-solving tasks: the original computer-based task and a reformatted task, where the computer agent was replaced by a human who could only choose his or her response from a small set of options.

- Teachers' opinions of their students' collaboration skills correlated well with their students' performance in the (computer-based) collaborative problem-solving assessment.

- Some students performed several collaborative problem-solving tasks with a computer agent and then two tasks face-to-face with another person, where they could interact freely instead of through a small set of multiple-choice options. Their performance with the computer agent was a moderately good predictor of their performance with the human partner.

So, while there are differences between how students collaborate with other people and how they collaborate with computer agents, the computer-based assessment used by PISA can still describe students' ability to collaborate with other humans.

\section{The bottom line}

So what should you look out for in late November when the collaborative problem-solving results are made public?

Among other things:

- Which country or economy has the highest average score in collaborative problem solving?

- As in PISA 2012, there is likely to be a positive relationship between performance in science, reading and mathematics, and performance in collaborative problem solving. If we compare students across different education systems who perform similarly in the three core PISA subjects, in which systems do students have the highest collaborative problem-solving performance?

- Do boys or girls perform better in collaborative problem solving?

- What are students' attitudes towards collaboration?

- Are there certain student behaviours or school policies associated with better performance in collaborative problem solving or with more positive attitudes towards co-operation? 


\section{For more information}

Contact: Jeffrey Mo (jeffrey.mo@oecd.org)

Coming next month: Do students know how to collaborate to solve problems?

This paper is published under the responsibility of the Secretary-General of the OECD. The opinions expressed and the arguments employed herein do not necessarily reflect the official views of OECD member countries.

This document, as well as any data and map included herein, are without prejudice to the status of or sovereignty over any territory, to the delimitation of international frontiers and boundaries and to the name of any territory, city or area.

This work is available under the Creative Commons Attribution-NonCommercial-ShareAlike 3.0 IGO (CC BY-NC-SA 3.0 IGO). For specific information regarding the scope and terms of the licence as well as possible commercial use of this work or the use of PISA data please consult Terms and Conditions on www.oecd.org. 